\title{
Heat Source Model in Arc Welding and Evaluation of Weld Heat-affected Zone*
}

\section{By Akira OKADA, ${ }^{* *}$ Takayoshi KASUGAI** and Kazuo HIRAOKA**}

\begin{abstract}
Synopsis
Concerning a heat source model for estimating thermal cycles near the fusion line in an arc welding from the heat conduction theory, the details of the frame model formed by line heat segments which correspond to heat transfers due to the plasma stream and molten metal flow have been proposed and can be determined using a personal computer system designed for the following steps:

1) Rough selection of line segments on the basis of an expert knowledge of the weld pool and simplification for practical use,

2) Evaluation of an effect of each segment on the thermal cycle by the multiple regression analysis, and

3) Checking adaptability of the segments from the distribution of the residuals and the time at a maximum temperature-elevation due to each segment.

As a result, the model for a given welding condition can be obtained on the basis of the data of the weld penetration measured by many engineers for a long time.

Moreover, the system to predict hardness and microstructural constituents in the heat affected zone and to determine optimum welding conditions has been developed by using an estimated thermal cycle and the database of CCT diagram for welding.
\end{abstract}

Key words: welding; heat conduction; modeling; weldability; weld thermal cycle; continuous cooling transformation diagram.

\section{Introduction}

The melting and thermal cycle in an arc welding have been studied by many researchers for a long time on the basis of the analytical solution of heat conduction by Rosenthal. ${ }^{11}$

However, in the redundant recent automatic arc welding processes with the higher current which produce deep penetration and a large volume of deposited metal, it is difficult to predict the penetration and thermal cycle on the basis of a point heat source adopted in Rosenthal's analysis.

Recently, computational processes for a complexly distributed heat source and various joint geometry have been studied.2) However, they are not easily applicable to the various practical conditions in arc welding since the results are obtained under limited conditions by a mainframe computer. For determining a welding condition, the system in which a computer one-sidedly gives only one answer from an experimental equation prepared in the program may be lacking in the flexibility and versatility.

In practical use, it is difficult but important to know how to determine a model as a substitute for an actual welding heat source and how to select an optimum welding condition.

A newly developed system has such an algorithm that the data based on welding engineer's experience or presumption are utilized in the process of computation. The system can solve the above problems by combining the computer's operational ability with the engineer's creativity and adaptability. The present system is designed for the interactive operations to overcome the following problems with repetition of trials :

1) Input of a desirable or expectant condition by the engineer,

2) Computation for checking reasonableness of the condition, and

3) Comparison of the result with an actual phenomenon or experience, and reconsideration of the initial condition.

\section{Outline of System for Evaluation of Heat- affected Zone}

In discussion of the welding condition to improve quality and reliability in an arc welding, it is necessary to estimate thermal cycles at various positions in the heat-affected zone (HAZ) and to predict the metallurgical transformation behavior.

This system consists of a heat conduction computing system and a database of the continuous cooling transformation (CGT) diagrams for HAZ using a personal computer as shown in Fig. 1.

First, a heat source model for a given welding condition is determined from the data of the relationship between a welding condition and representative sizes of the weld pool from the result to be discussed in Chap. III.

Next, the region of HAZ and thermal cycles are estimated by computing heat conduction using the heat source model determined in the first step.

Finally, the microstructural constituents and mechanical properties in HAZ are evaluated from the

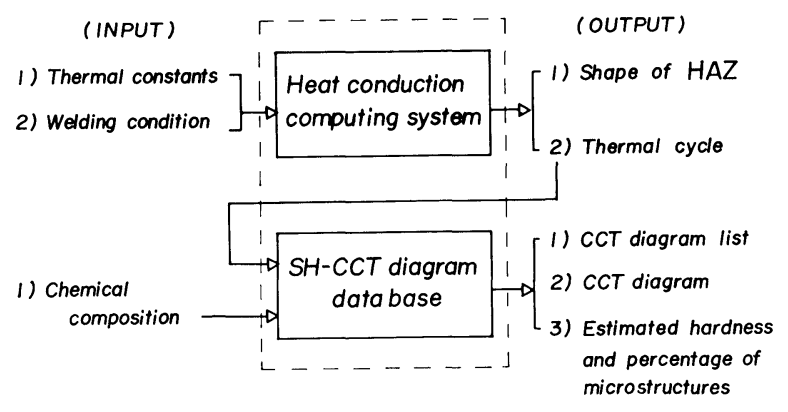

Fig. 1. Functions of the weld heat conduction simulator.

\footnotetext{
* Manuscript received on December 17, 1987; accepted in the final form on February 12, 1988. (C) 1988 ISIJ

** Advanced Materials Processing Division, National Research Institute for Metals, Nakameguro, Meguro-ku, Tokyo 153.
} 
thermal cycle and the database of the CGT diagrams to be discussed in Chap. IV.

\section{Determination of Heat Source Model}

\section{Calculation of Weld Thermal Cycle}

In computation of the heat conduction for the weld thermal cycle near the fusion line in an arc welding, it is difficult but important to know how to substitute a distributed heat source for an actual welding heat source.

Thermal cycles near the fusion line are influenced by heat transfer associated with weld pool formation; that is, supplies of arc heat in the direction of plate thickness due to plasma jet pressure and along the weld pool sides due to molten metal flow, and discharge of the stored heat in reinforced metal.

As for the prediction of thermal cycles, numerical analysis is available in which the contour of weld pool is treated as the fusion boundary. ${ }^{2)}$ However, it is not easy to know the three-dimensional shape of fusion boundary for a given welding condition and to input the coordinates of many points on the three-dimensional surface into a computer.

The aim of this study is to propose a simplified heat source model to predict the thermal cycles at various positions near the fusion line on the basis of the penetration depth and crater shape which are easily obtained from the experiment.

This method can utilize the data of relationship between welding parameters and representative sizes of the weld pool which have been accumulated by many engineers for a long time.

The analytical solution for a moving point heat source in a plate of finite thickness by Rosenthal ${ }^{1)}$ is used for computation of the heat conduction in this system.

The temperature-elevation at moving coordinates $(\xi, y, z)$ is

$$
\mathcal{T}=\frac{Q}{2 \pi K} \sum_{n=-\infty}^{n=\infty} \frac{e^{-\lambda v\left(\xi+R_{n}\right)}}{R_{n}}
$$

where, $K$ : $\quad$ conductivity $\left(\mathrm{J} / \mathrm{mm} \cdot{ }^{\circ} \mathrm{C} \cdot \mathrm{s}\right)$

$Q:$ heat input $(\mathrm{J} / \mathrm{s})$

$R_{n}=\sqrt{\xi^{2}+y^{2}+(2 n t+z)^{2}}$

$S$ : time from passing of electrode above measuring point for thermal cycle ( $\mathrm{s}$ )

$t:$ plate thickness $(\mathrm{mm})$

$v$ : welding velocity $(\mathrm{mm} / \mathrm{s})$

$\xi:-v \cdot s(\mathrm{~mm})$

$\rho c: \quad$ volume specific heat $\left(\mathrm{J} / \mathrm{mm}^{3} \cdot{ }^{\circ} \mathrm{C}\right)$

$\lambda: \quad \rho c / 2 K\left(\mathrm{~s} / \mathrm{mm}^{2}\right)$.

In this study, a line segment formed by some moving point-heat sources is arranged in a straight line as will be metntioned in the following. Temperature of an arbitrary location in the plate is given by the summation of temperature-elevation at the location due to each point-heat source.

\section{Heat Source Model Composed of Line Heat Segments}

A heat source model must be designed so that the thermal cycle is more accurately estimated and the three-dimensional shape of weld pool is simulated more simply.

In this study, the weld pool is expressed as combining line heat segments like a frame. The reason for adopting such a model is to make the input of data on the model and computation quick and easy. Moreover, the line segments can correspond to the directions of heat transfer in the weld pool.

For example, the heat transfer in the direction of penetration depth due to plasma jet, as shown in Fig. 2, is approximately expressed with a line heat segment in the direction. Also, the supplies of arc heat along the weld pool sides due to molten metal flow may be expressed with some line segments put in the direction of the flow on the pool.

From a knowledge on the heat transfers in the weld pool, a heat source model composed of line segments can be assumed as shown in Fig. 3. However, the exact position, length and heat input of each segment are not definite on this figure. Moreover, some additional line segments may be necessary. These unknown quantities can be estimated by using a system on the basis of multiple regression analysis of experimental results, because temperature of an arbitrary location in the plate is given by the summation of temperature-elevation at the location due to each segment.

\section{System for Determining Heat Source Model}

In this study, the following rules are assumed in determination of the line heat segments for a heat source model.

(1) On the basis of observations on a welding arc

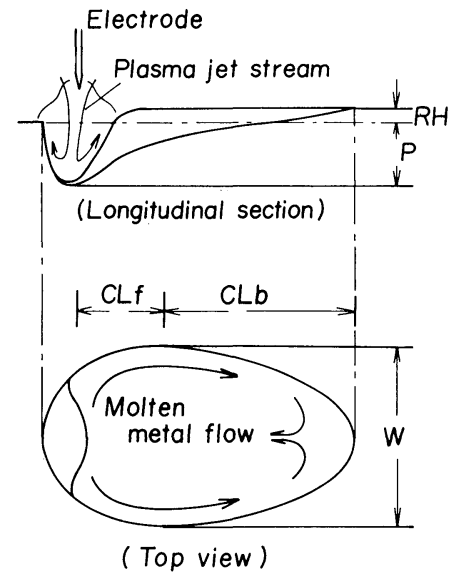

Fig. 2. A weld pool in gas metal arc welding.

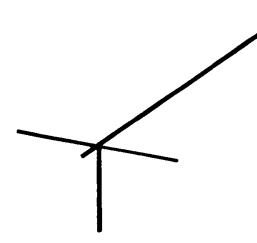

(A)

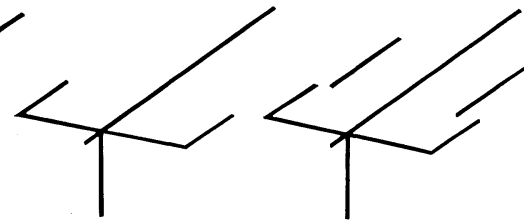

(B)
(C)
Fig. 3. Configurations of line heat segments expected from the weld pool. 
and pool, a rough configuration of line heat segments is expected as shown in Fig. 3. As for the distribution of heat quantity to the line segments due to molten metal flow, heat input per unit length of a line segment may be constant in each part if the pool is divided into the front part $C L_{f}$ and back part $C L_{b}$.

(2) From the practical point of view, the heat source model must be simplified at most. Therefore, a line segment is set parallel to each axis of $X, Y$, or $Z$ and its length is determined from a representative size of the pool shape. The heat is distributed uniformly on the segment.

(3) In order to select the line segments for an optimum heat source model from the expected candidates, the temperature-elevation calculated from each candidate per unit heat input is used as a predictor variable and a stepwise method in multiple regression analysis is carried out by using each of measured thermal cycles at the toe and root as a criterion variable.

(4) Residuals in the time range of the thermal cycle are investigated and the necessity of addition of some line segments is examined to compensate the larger residuals. Accordingly, the time at maximum temperature in the temperature-time curve calculated from each candidate is investigated and then if the time is not in the range of the larger residuals, a new candidate as the time is in the range has to be reconsidered.

The rules mentioned above are applied in determination of a heat source model shown by a flowchart in Fig. 4.

Weld thermal cycles at the toe and root and representative sizes of the weld pool shape such as penetration depth and bead width are measured for various welding conditions in advance.

The line heat segments expected from a weld pool shape according to the rules (1) and (2) are input into this system as candidates for a heat source model in block (I).

First in block (II), the line segment in the direction of penetration depth due to plasma jet of arc is adopted as a component of the model. In this block, selection for inclusion or exclusion of a line segment is made by the multiple regression analysis.

Then, the line segment which has the largest influence on an increase in coefficient of determination is investigated from the other candidates and is adopted as a component. By this added segment, if there arises a component with a decreased influence below

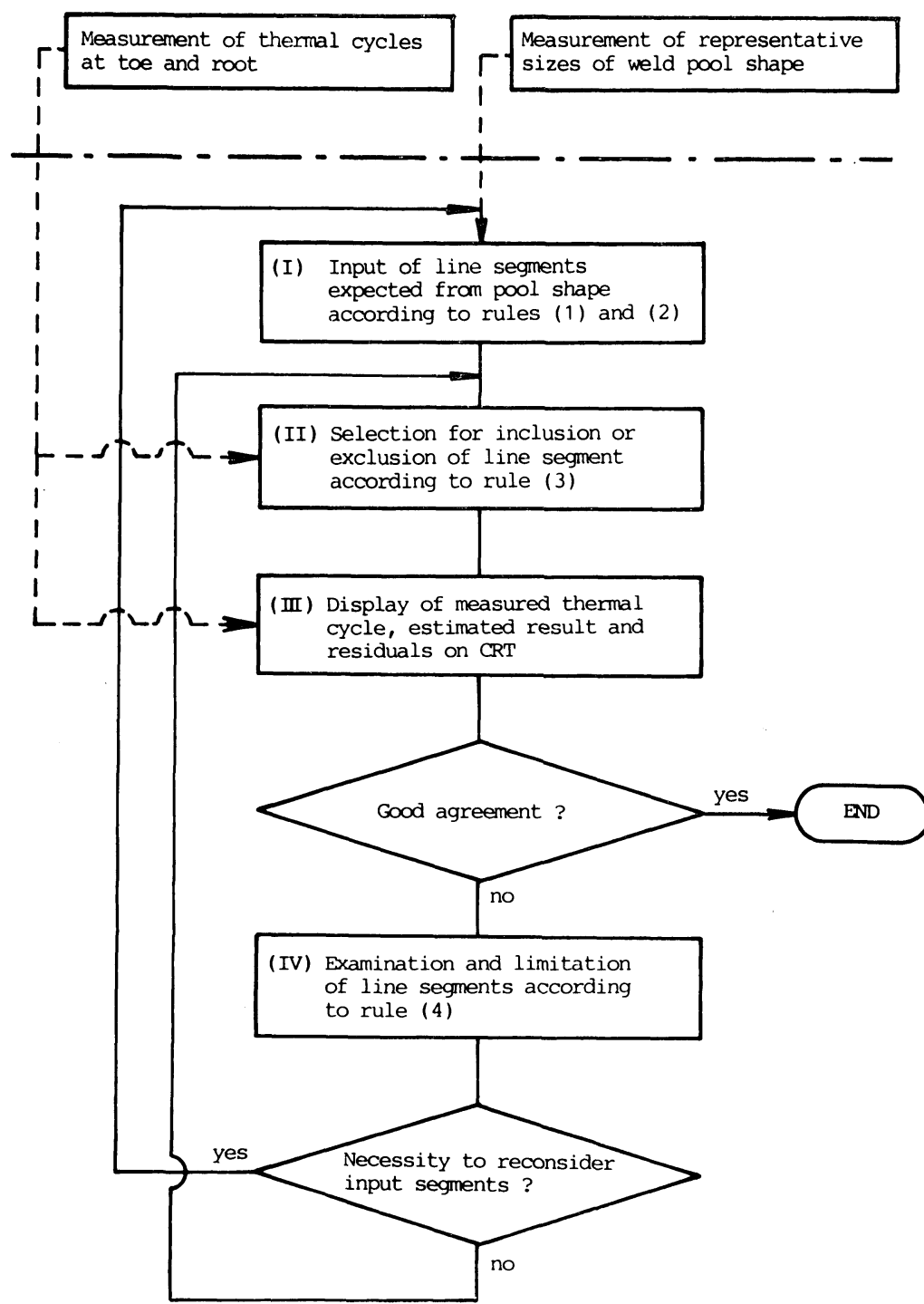

Fig. 4.

Determination of a heat source model on the basis of multiple regression analysis. 
a limit, the component is excluded from the selected components.

Next, the measured thermal cycles and estimated results by multiple regression are respectively compared on the GRT display in block (III). If there is a partial range in which residuals are larger, another line segment has to be selected to amend the residuals in the range. If the result is satisfactory, the selected line segments are determined as the heat source model.

In block (IV), some line segments which are more probable to be selected next are checked by the rule (4) in candidates. If the line segment which has an influence on the larger residual range is not included in the input candidates, a new suitable candidate have to be input at the block (I).

\section{Examples of Measured Thermal Cycle and Determined Model}

Figure 5 shows measured thermal cycles at the toe (surface) and root of the fusion line in $\mathrm{CO}_{2}$ shielding gas metal arc welding (Test No. 2). A carbon steel plate of $30 \mathrm{~mm}$ in thickness was drilled at the predetermined positions for setting a thermocouple from the back surface to measure thermal cycles. The welding parameters are $450 \mathrm{~A}$ in the welding current, $39.5 \mathrm{~V}$ in arc voltage and $5 \mathrm{~mm} / \mathrm{s}$ in travel speed.

Figure 6 shows the case of $\mathrm{Ar}-\mathrm{CO}_{2}$ mixture shielding gas (Test No. 11). The welding parameters are the same as the above expect for the voltage of $30 \mathrm{~V}$.

As the results, the thermal cycle at the root is very different from the toe. This means that these thermal cycles can not be expressed with a simple heat source model.

The details of the configuration and required heat quantity for each line segment can be discussed from

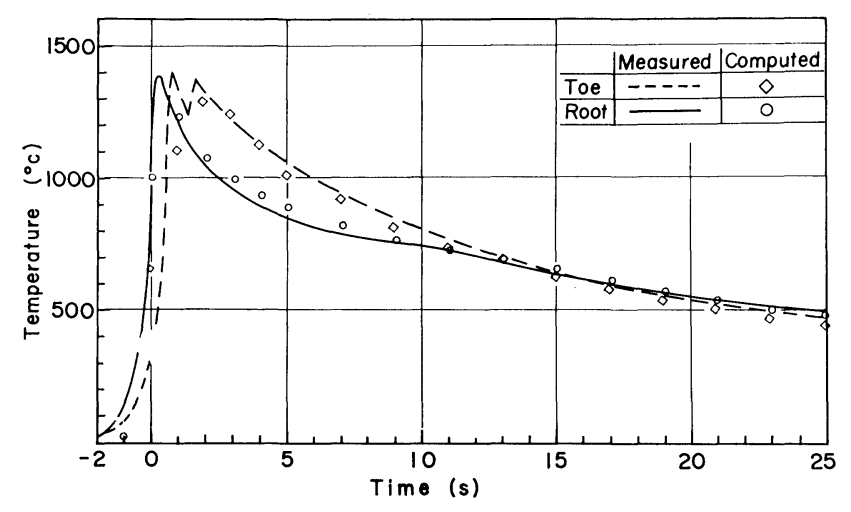

Fig. 5. Thermal cycles at the toe and root of fusion line in $\mathrm{CO}_{2}$ arc welding (Test No. 2). these measured thermal cycles on basis of the multiple regression analysis.

A heat source model as shown in Fig. 7 and Table 1 has been established by repetition of the procedure shown in the flowchart in Fig. 4.

The segments positioned on and above the surface are symmetrical with respect to the weld center line, and the segments on the right side of the welding line consist of 5 lines (2) to (6) shown in Fig. 7. The symbols $C L_{f}$ and $C L_{b}$ represent the length along $X$-axis from electrode to the point of maximum crater width and from the point to crater end, respectively (see Fig. 2).

The characteristics near the peak of the thermal cycle at the toe can not be expressed by only one line segment which corresponds to the length of $C L_{f}$ in Fig. 7. Therefore, the line segment is divided into two halves ((3), (4)) and separated with $1 \mathrm{~mm}$ gap.

The segments (5) and (6) which correspond to the back of the pool are positioned above the plate surface according to the height of reinforced metal to approximate the effect of the reinforcement.

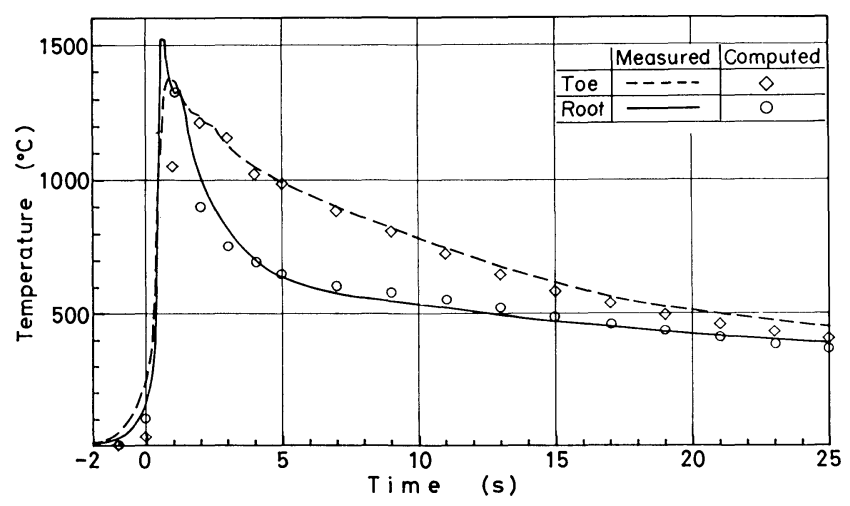

Fig. 6. Thermal cycles at the toe and root in $\mathrm{Ar}-\mathrm{CO}_{2}$ arc welding (Test No. 11).

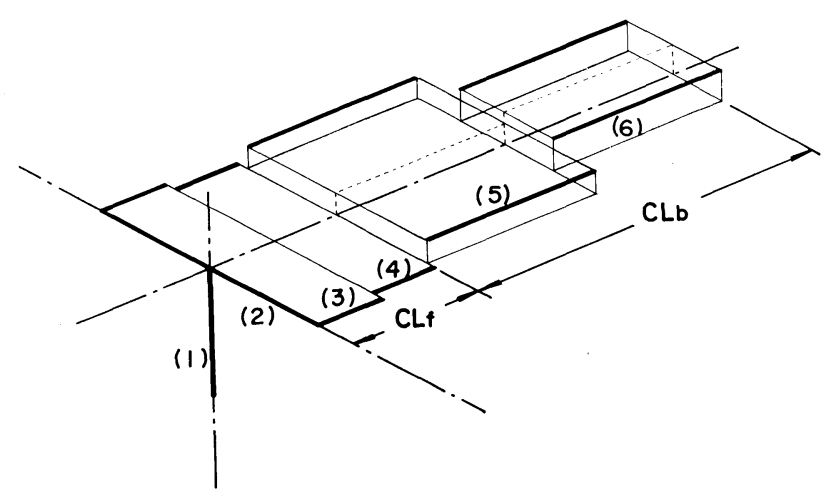

Fig. 7. Determined configuration of line heat segments.

Table 1. Determined heat source model.

\begin{tabular}{|c|c|c|c|c|c|c|c|c|}
\hline \multirow{2}{*}{$\begin{array}{l}\text { Test } \\
\text { No. }\end{array}$} & \multicolumn{4}{|c|}{ Length (mm) } & \multirow{2}{*}{ Multiple regression model } & \multirow{2}{*}{$\begin{array}{l}\text { Sum of partial } \\
\text { regression } \\
\text { coefficient }\end{array}$} & \multicolumn{2}{|c|}{$\begin{array}{l}\text { Coefficient of deter- } \\
\text { mination }\end{array}$} \\
\hline & $L_{1}$ & $L_{2}$ & $L_{3}, L_{4}$ & $L_{5}, L_{6}$ & & & (toe) & (root) \\
\hline 2 & 7 & 11 & 8 & 18 & $\begin{aligned} T & =6138 \cdot T_{1}+1795 \cdot T_{2}+1498 \cdot T_{3} \\
& +1498 \cdot T_{4}+1498 \cdot T_{5}+1498 \cdot T_{6}\end{aligned}$ & $13925 \mathrm{~J} / \mathrm{s}$ & 0.971 & 0.927 \\
\hline 11 & 10 & 9 & 6 & 12 & $\begin{aligned} T & =6276 \cdot T_{1}+1163 \cdot T_{2}+933 \cdot T_{3} \\
& +933 \cdot T_{4}+1448 \cdot T_{5}+1448 \cdot T_{6}\end{aligned}$ & $12201 \mathrm{~J} / \mathrm{s}$ & 0.983 & 0.977 \\
\hline
\end{tabular}


As mentioned above, the line segments corresponding to heat transfer due to molten metal flow are in configuration roughly on the contour of the actual weld pool surface. It is interesting that the line segment on the weld center line shown in Fig. 3 is excluded.

In the Figs. 5 and 6 , the results plotted with circular, triangular and square symbols were estimated from the multiple regression in Table 1 and agree well with the respective measured results shown by lines.

\section{Relationship between Heat Source Model and Sizes of Weld Pool}

Each of predictor variables $T_{1}, T_{2}, \ldots, T_{6}$ of multiple regression model in Table 1 is the temperatureelevation per unit heat input due to each of line segments (1), (2), ..., (6), respectively. Then, its coefficient of determination means each heat input $Q_{p}(p=1,2, \ldots, 6)$ given to each segment under the welding condition.

Therefore, the sum of these coefficients in the model will be equal to the total heat input given to the weld pool, $Q(=\operatorname{arc}$ efficiency $(\eta) \cdot \operatorname{voltage}(E) \cdot \operatorname{current}(I) /$ $100, \mathrm{~J} / \mathrm{s})$.

In the case of Test No. 2 in Table 1, the arc efficiency may be $78 \sim 80 \%$ for the higher arc voltage, but in the test No. 11, it may be $90 \%$. Each heat input calculated thereby agrees with the sum of the coefficients in Table 1.

By comparing the model obtained in this manner with the measured weld pool shape, a general relationship between the model and respective sizes of the pool can be found.

For example, in the case of gas metal arc welding with the higher current as shown in Figs. 5 and 6, the total heat quantity $Q_{5,6}$ assigned to line segments (5) and (6) is proportional to a reinforcement area $R A$ $\mathrm{mm}^{2}$ of the weld bead and the ratio of the total heat quantity $Q_{2,3,4}$ for the front of the pool surface to the heat quantity $Q_{1}$ for the pool depth is expressed approximately as a function of $P / W$ ratio, as shown in Fig. 8.

By obtaining those relationships for each arc welding process, the data of the representative sizes of weld pool which have been measured by many engineers can be utilized to determine a suitable heat source model for a given welding condition.

\section{CCT Diagram Database}

In CGT diagram database, about 200 sheets of CGT diagrams for low carbon and low alloyed steels have been stored and an optimum CCT diagram for a given steel can be selected.

Using man-machine interactive operation, an engineer can estimate the percentage of microstructural constituents and the hardness from a selected CCT diagram, which is composed of the measurement values and not used an estimation formula like $P \mathrm{~cm}^{3)}$ and hardness. ${ }^{4)}$

The following three basic procedures have been developed for the selection of a CCT diagram which the

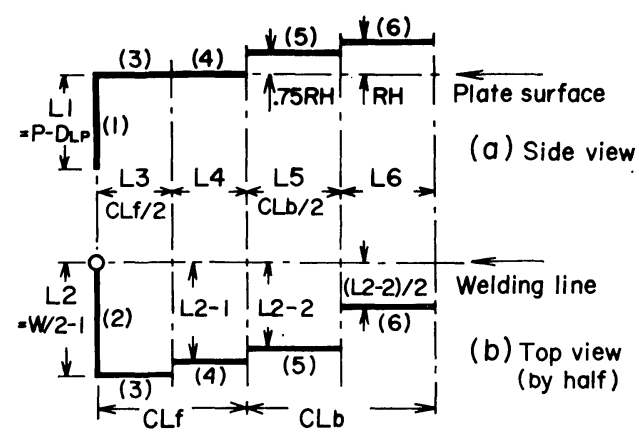

$$
\begin{aligned}
& \mathbf{Q}, 3,4 / \mathbf{Q} 1=1 \cdot 325-1.5 \cdot \mathbf{P} / \mathbf{W} \\
& \mathbf{Q} 5,6=1800 \cdot \mathbf{C} \boldsymbol{\rho} \cdot \mathbf{V} \cdot \mathbf{R A} \cdot 10^{-12} \\
& \mathbf{Q} 2,3,4=(\eta \cdot \mathbf{E} \cdot \mathbf{I} / 100)-\mathbf{Q} 1-\mathbf{Q} 5,6 \\
& \mathbf{Q} 5 / \mathbf{L} 5=\mathbf{Q} 6 / \mathbf{L} 6 \\
& \mathbf{Q} 2 / \mathbf{L} 2=\mathbf{Q} 3 / \mathbf{L} 3=\mathbf{Q} 4 / \mathbf{L} 4
\end{aligned}
$$

Fig. 8. Example of relationship between the heat source model and representative sizes of the weld pool for gas metal arc welding.

engineer may wish to use.

(1) Procedure I is used for the selection of GCT diagrams from the steel composition up to 11 elements.

There is no problem, if the database contains a CGT diagram with the same composition as the input value. Even though the database dose not contain the CCT diagram with the same composition as the input data, CGT diagrams for the nearest compositions to input data can be selected from the database. In order to obtain a desirable or approximate CCT diagram from the database, the acceptable limits of composition variation for each element were set in the ranges as shown in Table 2. This criterion was established on the basis of studies ${ }^{5)}$ on the effect of alloying elements on the CCT diagram and of many experiments obtained during making of the CCT diagrams.

In the database, if there is no GCT diagram with 11 elements, which satisfactorily meet the criterion in Table 2, CCT diagrams in which only one or two elements deviate from the criterion ranges are selected.

(2) Procedure II is used to study the effect of certain elements on the CCT diagram. When composition ranges of elements other than the objective element or elements are set, CCT diagrams in this range containing different levels of objective elements are searched and displayed. The engineer is also able to input a composition range for all 11 elements using Procedure II. This allows a steel selection criterion to be made by the engineer himself as a supplementary method to Procedure I. The engineer is able to estimate the CGT diagram by means of an extrapolation or interpolation from two overlapped CGT diagrams on the CRT.

(3) Procedure III is used for the investigation of the relationship between chemical composition and CGT characteristics, or a steel selection suitable for some welding conditions such as limiting welding heat 
Table 2. Composition range for selection of CCT diagram in procedure $\mathrm{I}$.

\begin{tabular}{ll}
\multicolumn{1}{c}{ Element } & \multicolumn{1}{c}{ Range of selection } \\
\hline $\mathrm{C}$ & {$[\mathrm{C}] \% \pm 0.02 \%$} \\
$\mathrm{Si}$ & {$[\mathrm{Si}] \% \pm 0.4 \times[\mathrm{Si}] \%$} \\
& {$[\mathrm{Si}] \% \pm 0.4 \% \quad($ at $[\mathrm{Si}] \% \geqq 1 \%)$} \\
$\mathrm{Mn}, \mathrm{Ni}, \mathrm{Cr}, \mathrm{Mo}$ & {$[\mathrm{M}] \% \pm 0.2 \times[\mathrm{M}] \%$} \\
& {$[\mathrm{M}] \% \pm 0.25 \% \quad($ at $[\mathrm{M}] \% \geqq 1.25 \%)$} \\
$\mathrm{V}, \mathrm{Al}, \mathrm{Ti}, \mathrm{Nb}, \mathrm{B}$ & yes or no \\
\hline
\end{tabular}

input. When ranges of CGT characteristics are input, CGT diagrams in this range are searched and displayed with the chemical composition and CGT characteristics.

For all procedures, the percentage of microstructural constituents and Vicker's hardness (load $10 \mathrm{kgf}$ ) are displayed on the CRT when the cooling time from $A_{3}$ or $A_{\mathrm{C} 3}$ to $500^{\circ} \mathrm{C}$ or a computed thermal cycle at a $\mathrm{HAZ}$ near the fusion line is input.

Although many CCT diagrams, TTT diagrams, and hardenability charts for heat treatments have been published so far, there is no database to evaluate easily heat treatment characteristics. It may be attributed to the difficulties to input the data on a complicated figure into a database. In order to store automatically these data in a computer, "CCT chart reader system" was developed ${ }^{6)}$ in this study, as shown in Fig. 9. This reader system is capable not only to apply to read CCT data for welding, but also to read every drawing data into a computer.

It is considered that this CCT database has a very practical use for the weldability evaluation of a steel and selection and development of steels.

\section{Selection of Optimum Welding Condition}

As a general example, the procedure for the selection of an optimum welding condition is described when a plate with known material properties is given. The procedure is shown in Fig. 10. Although the flowchart is for determination of welding condition, these is a setting of the welding parameters in step (2) which is a feature of the system as mentioned in Chap. I. Desirable condition may be set at this step from various viewpoints such as an engineer's experience, limitation for welding and productivity.

Next, a database of relationship between welding parameters and the representative sizes of the weld pool shape is searched for all the data necessary for statistical estimation of the sizes for the input parameters.

In step (4), if the sizes are different from engineer's anticipation, welding parameters are again set at the step (2). If the result is satisfactory, a heat source model is determined from the sizes at step (4).

Next, the heat-affected zone boundary is computed from the model. The position is designated by moving the cursor on CRT, referring to the display. Computed thermal cycle is displayed and drawn on a $X Y$-plotter if necessary in step (7).

Next, with regard to the display of memorized CGT

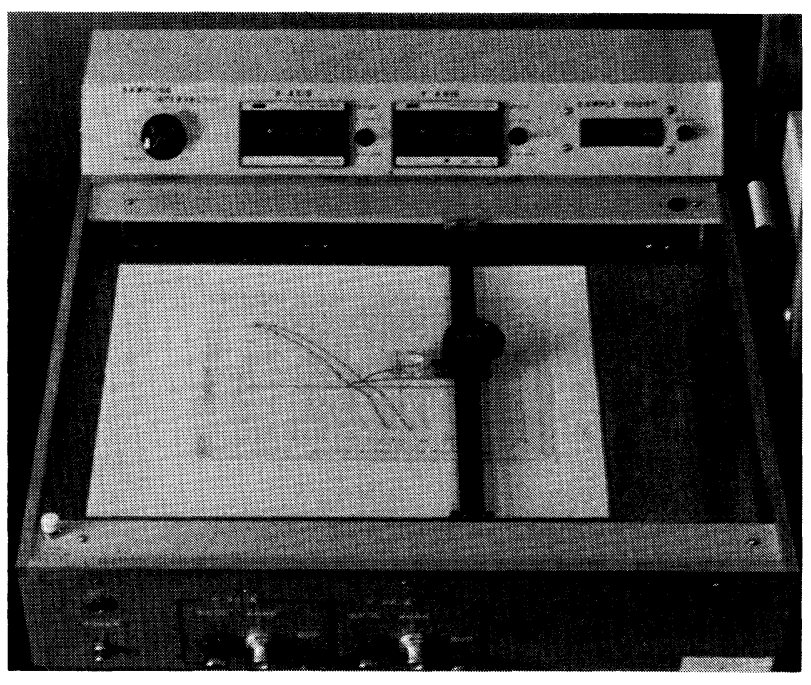

Fig. 9. CGT chart reader system.

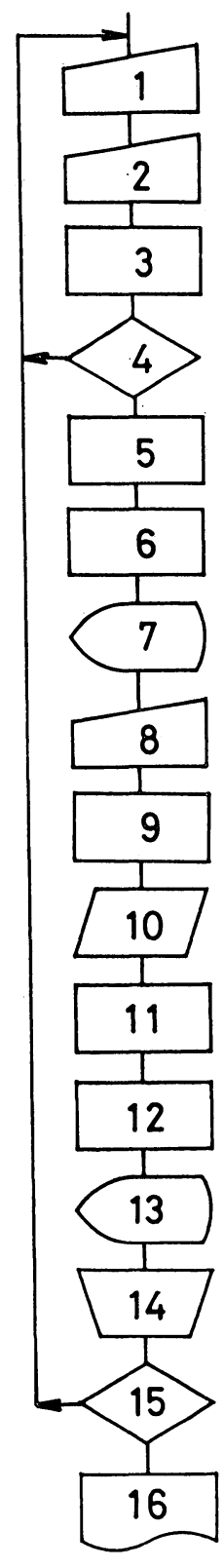

Input of thermal constants of material

Input of desirable or expectant welding parameters

Statistical estimation of weld pool sizes using the database

If the result is unsatisfactory, go to (2)

Determination of heat source model from weld pool sizes

\section{Computation of HAZ boundary}

Display of region of $\mathrm{HAZ}$

Input of co-ordinates to be computed weld thermal cycle

Computing the thermal cycle

Plotting the thermal cycle

Display and comparison of memorized SH-CCT diagrams (200 types)

Estimate of hardness and percentage of microstructural constituents

Display the result

Reference to data of mechanical properties

If the result is unsatisfactory, go to (2)

Printing out input data and all results

Fig. 10. Flowchart for selection of optimum welding condition in an arc welding on a steel plate. 


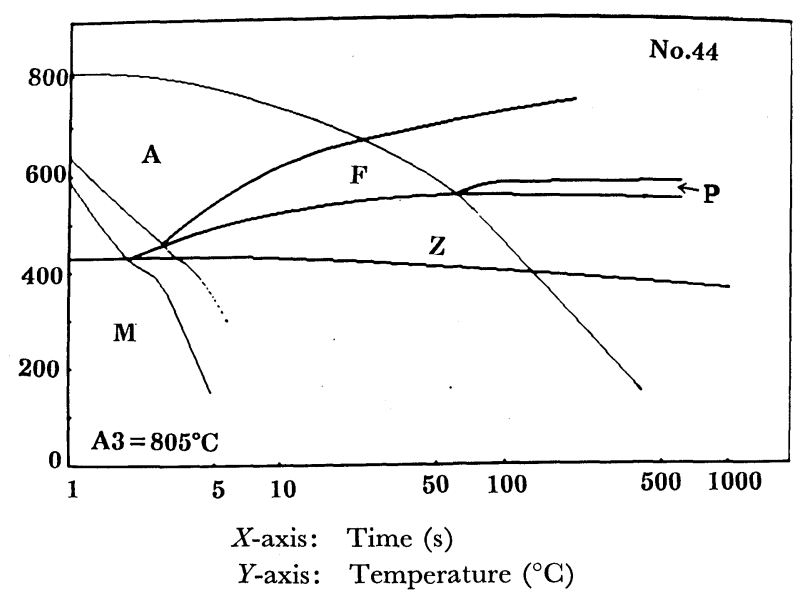

Fig. 11. Display of CGT diagram for welding.

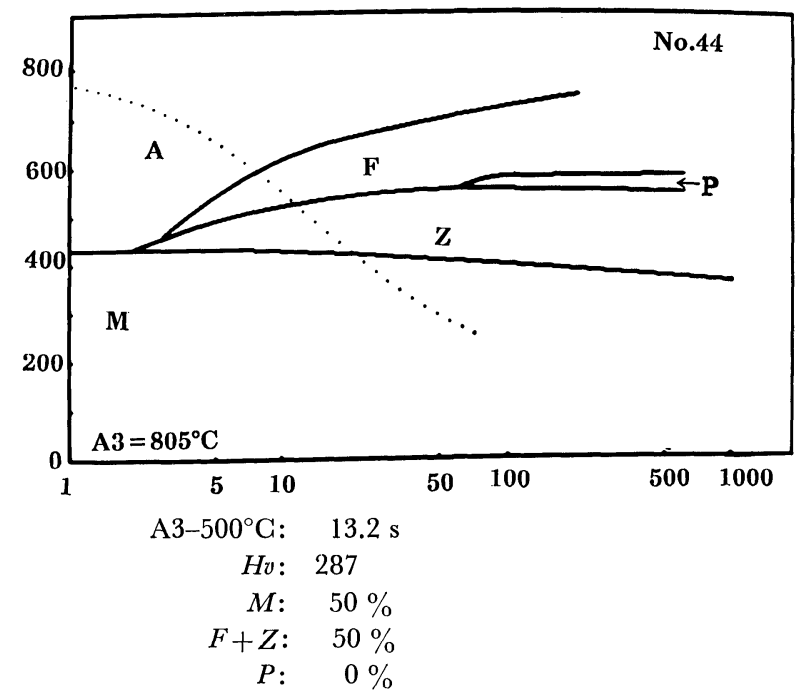

Fig. 12. Estimation of hardness and percentage of microstructural constituents.

diagram, when the chemical composition of a steel to be welded is set, the system selects some CCT diagrams with compositions similar to the input from the approximately 200 memorized sheets and a list of 5 to 10 recommended diagrams is displayed on CRT. The engineer selects a suitable one from the list and its CCT diagram is drawn on CRT as shown in Fig. 11. Hereupon, if the computed thermal cycle is put on the displayed CCT diagram, the estimated values of hardness and area percentage of each microstructure are shown in the lower part of the CGT diagram as shown in Fig. 12.

If these are critical cooling curves in a GCT diagram for the particular properties such as weld cracking, notch toughness, etc. as database, these data can be referred.

If the engineer satisfies himself of the result, the input data and all the result are printed out.

\section{Conclusion}

The system using an interactive personal computer is proposed to analyze a heat source model for welding heat conduction and to evaluate welding condition. The method for determination of the model and procedure for selection of optimum welding condition are discussed on the basis of the data of weld pool shape and CCT diagrams for welding.

The following conclusions have been formulated as a result of this study.

(1) In a frame model formed by line heat segments for weld heat conduction, the details of the configuration and required heat quantity for each segment can be evaluated from the multiple regression analysis. Here, a criterion variable is each of measured thermal cycles at the toe and root, and each predictor variable is the temperature-elevation at the measured position per unit heat input due to each line segment.

(2) The optimum heat source model can be determined by the computer system designed for the following steps:

(I) Rough selection of line segments on the basis of an expert knowledge of the weld pool and simplification for practical use,

(II) Evaluation of an effect of each segment on the thermal cycle by the multiple regression analysis, and

(III) Checking adaptability of the segments from the distribution of the residuals and the time at a maximum temperature-elevation due to each segment.

(3) By obtaining a general relationship between the heat source model and weld pool sizes for each arc welding process, the data of the representative sizes of weld pool which have been measured by many engineers can be utilized to determine a suitable model for a given welding condition.

(4) An estimated thermal cycle and the database of CCT diagram for welding can predict hardness and microstructural constituents in HAZ for a given condition and can determine optimum welding parameters for a plate to be welded.

\section{REFERENGES}

1) D. Rosenthal: Weld. J., 20 (1941), 210s.

2) Z. Paley and P. D. Hibbert: Weld. J., 54 (1975), 385s

3) Y. Ito and K. Bessho: IIW Doc. IX-576-68, (1968).

4) N. Yurioka, S. Ohshita and H. Tamehiro: Austl. Weld. Res. Assoc. Symp. "Pipeline Welding in the 80's", March 1981, Melbourne.

5) M. Inagaki and T. Kasugai: Rep. Nat. Res. Inst. Met., 14 (1971), 154, (in Japanese).

T. Kasugai and M. Inagaki: Trans. Nat. Res. Inst. Met., 22 (1980), 258; 23 (1981), 44, 109 \& 191; 24 (1982), 22.

6) T. Yokogawa and I. Yamamoto: Trans. Soc. Instrum. Control Eng., 20 (1984), 241. 